\title{
Health Status, Intention to Seek Health Examination, and Participation in Health Education Among Taxi Drivers in Jinan, China
}

\author{
Yan Yang ${ }^{1,}$; Xiao-sheng Fan $^{2}$; Cui-huan Tian ${ }^{1}$; Wei Zhang ${ }^{1}$; Jie Li ${ }^{1}$; Shu-qing Li $^{1}$ \\ ${ }^{1}$ Health Examination Center, QiLu Hospital of Shandong University, Jinan, China \\ ${ }^{2}$ Department of Cardiology People's Hospital of LaiWu, LaiWu, China \\ *Corresponding Author: Yan Yang, Health Examination Center, QiLu Hospital of Shandong University, Jinan, China. Tel:+86-53182166920, Fax: +86-53182166921, E-mail: yangyan1021@ \\ tom.com
}

Received: July 3, 2013; Revised: August 20, 2013; Accepted: September 20, 2013

\begin{abstract}
Background: Taxi drivers are exposed to various risk factors such as work overload, stress, an irregular diet, and a sedentary lifestyle, which make these individuals vulnerable to many diseases. This study was designed to assess the health status of this occupational group. Objectives:The objective was to explore the health status, the intention to seek health examination, and participation in health education among taxi drivers in Jinan, China.

Patients and Methods: The sample-size was determined scientifically. The systematic sampling procedure was used for selecting the sample. Four hundred taxi drivers were randomly selected from several taxi companies in Jinan. In total, 396 valid questionnaires (from 370 males and 26 females) were returned. Health status, intention to seek health examination, and participation in health education were assessed by a self-designed questionnaire. Other personal information including sex, age, ethnicity, marital status, years of employment as a taxi driver, education level, and habits were also collected.

Results: This survey revealed that $54.8 \%$ of taxi drivers reported illness in the last two weeks and $44.7 \%$ of participants reported chronic diseases. The prevalence rates of hypertension, diabetes mellitus, gastroenteritis, arthritis, and heart disease were $18.2 \%, 8.8 \%, 26 \%, 18.4 \%$, and $4.8 \%$ of questioned taxi drivers, respectively. Significant self-reported symptoms included fatigue, waist and back pain, headache, dyspepsia, and dry throat affecting $49.7 \%, 26.2 \%, 23.5 \%, 26 \%$, and $27 \%$ of participants, respectively. In total, $90.1 \%$ of subjects thought that it was necessary to receive a regular health examination. Only $17.9 \%$ of subjects had been given information about health education, and significantly, more than $87 \%$ of subjects who had been given information about health education reported that the information had been helpful.

Conclusions: Taxi drivers' health was poor in our survey. Thus, using health education interventions to improve knowledge and change in behaviors are necessary and effective programs that improve the health of individuals in this special occupational group are needed.
\end{abstract}

Keywords:Health Status; Health Surveys; Occupational Disease; Health Education; Health Services Needs and Demand

\section{Background}

In China, the "taxi" industry is an important component of the transportation industry that makes significant contributions to the city development. However, taxi drivers' physical and mental health is poor. The average working time is 10.5 hours per day for 6.4 days per week, and these individuals spend an average of 3.5 hours waiting for passengers each day. Most taxi drivers have little education and a lack of economic, social, or human capital. Due to work overload, monotony, boredom, repetition, and the stress of coping with various traffic conditions, these drivers have a high risk of damaging the human biological clock rhythm and are at risk of fatigue, depression, tension, insomnia, and other diseases. Although most taxi drivers suffer from work-related diseases, to the best of our knowledge, few studies have explored the health status, the intention to seek health ex- amination, and participation in health education among taxi drivers in China.

\section{Objectives}

For existing problems, we decided to conduct a study to explore the health status, the intention to seek health examination, and participation in health education among taxi drivers in Jinan, China.

\section{Patients and Methods}

\subsection{Ethics Statement}

This study used a descriptive design. The consent protocol and the procedure were approved by the Ethics Committee of Qilu Hospital of Shandong University, China. Participation in the study was completely volun- 
tary and if participants did not wish to participate they would have the option of declining to answer specific questions or leaving the entire questionnaire blank. The survey was anonymous and the data were presented in an aggregated manner, hence, the participants' privacy and confidentiality would be firmly protected. All these policies were also printed in the front cover of the questionnaire. Informed written consent was received from all participants.

\subsection{Demographic Characteristics}

We obtained data from a cross-sectional survey conducted in Jinan, the capital of Shandong Province, China. We performed the survey from December 2012 to April 2013. Company-employed or self-employed taxi drivers were the targeted population. The sample-size was determined using the statistical cluster-sampling technique according to the formula: $\mathrm{n}=\mathrm{p}(1-\mathrm{p}) \mathrm{NZ}^{2} / \mathrm{Nd}^{2}+\mathrm{Z}^{2} \mathrm{p}(1-$ p). In total, 400 taxi drivers were randomly selected from several taxi companies in Jinan. Finally, 396 valid questionnaires were returned. The valid sample comprised 370 males and 26 females. A self-administered questionnaire was used to collect personal information including sex, age, ethnicity, marital status, years of employment as a taxi driver, and education level. Educational level was categorized into five categories: elementary school (i.e., people who attended up to six years of schooling), junior high school (i.e., 7-9 years of schooling), senior high school (i.e., 10-12 years of schooling), college, and university or higher (i.e., complete or incomplete post-secondary school).

\subsection{Clinical Characteristics}

Self-rated physical health was measured based on responses to the question "how would you rate your overall physical health?" using a five-point Likert-type scale, where $1=$ excellent, 2 = good, $3=$ fair, $4=$ poor, and $5=$ very poor. these five points are recommended by the World Health Organization (WHO) (1). On this scale, high scores indicate a better health status. Respondents were surveyed by asking "have you had any physical and mental discomfort during the past two weeks?" and "have you ever been diagnosed with chronic disease during the past 12 months?". Those individuals who answered "yes" to the above questions were defined as having a clinical characteristic.

The history of disease was collected if an individual had been diagnosed with a chronic disease, such as hypertension, diabetes mellitus, heart disease, stroke, emphysema, ulcer, a liver condition, arthritis, weak/failing kidneys, asthma, cancer, or other medical conditions within 12 months prior to the survey. A chronic ailment is defined as an ailment that lasts or is expected to last for at least 12 months resulting in functional limitations or the need for ongoing medical services and includes disability (2). Non-physician-diagnosed chronic disease was not included. Physician-diagnosed chronic disease was further confirmed by asking about the location of diagnosis, including community clinics, county hospitals, city hospitals, provincial hospitals and military hospitals. The reported diseases were coded and classified using the disease classification scheme designed by China Ministry of Health for the survey.

Two widely used generic health-related quality-of-life measures are the EQ-5D and the 12-item short-form health survey (SF-12) (3-5). Based on them, we created a summary self-designed symptom questionnaire according to our actual situation. This questionnaire included questions about the most common symptoms. Other information about the intention to seek health examination and participation in health education was also recorded using our self-designed questionnaire.

\subsection{Habits}

To characterize health habits, we included data on the smoking status, alcohol consumption, irregular dietary habits, average working time per day, average sleeping time per day, and the frequency of physical activity. Smoking status was dichotomized as current smoker ( $\geq$ 1 filter per day) and nonsmoker. For physical activity assessment, exercise was grouped as "no" or "yes" for regular exercise, with people reporting "no planned walking" allocated into the "no" group, whereas any other planned exercise, including walking, was considered as eligible for the "yes" group.

\subsection{Data Collection}

Medical doctors and nurses at our center conducted the survey. Under the investigators' guidance, the respondents completed the questionnaire themselves. For quality control, the completeness of the questionnaire was checked at the end of the survey. If there were missing data, individuals would be re-surveyed.

\subsection{Statistical Analysis of Results}

Proportions were employed to describe respondents' basic characteristics and health status. Certain data were presented as the mean \pm standard deviation $( \pm S D)$. Because the number of females was small, we do not describe these individuals separately, and the P-value was not reported. SPSS version 10 (SPSS Inc, Chicago, Illinois, USA) was used for all statistical analyses. Ninety-five percent confidence interval (CI) was calculated for each variable.

\section{Results}

\subsection{Basic Characteristics}

The basic characteristic data of the respondents are presented in Table 1. Four hundred questionnaires were distributed, and 396 valid surveys were returned with a sur- 
Yang Yet al.

vey response rate of 99\%. Participants' age ranged from 20 to 60 years, and the average age in the sample was $36.5 \pm 2.9$ years. Most respondents were married (79.5\%). Our survey revealed that more than $93 \%$ of taxi drivers were male (370 men), 70\% were between 30 and 50 years of age, and 50\% had junior high school education or below. The average number of years of employment as a taxi driver was 8.5 years.

\subsection{Habits}

Based on Table 2, of the respondents, approximately $76.5 \%$ were current smokers, $10.3 \%$ drank alcohol frequently, $66.9 \%$ had irregular diets, and $85 \%$ reported no regular exercise. The average working time was 10.5 hours per day and the average sleeping time was 6.9 hours per day.

\subsection{Self-reported Chronic Diseases}

As shown in Table 3 and 4, a total of 17 subjects (4.3\%) rated their health as excellent, $123(31 \%)$ as good, 166 (41.9\%) as fair, $83(20.9 \%)$ as poor, and 7 (1.7\%) as very poor. Additionally, $54.8 \%$ reported illness in the last two weeks, and $44.7 \%$ reported chronic disease. The self-reported prevalence rates of hypertension, diabetes mellitus, gastroenteritis, arthritis, and heart disease were $18.2 \%, 8.8 \%, 26 \%, 18.4 \%$, and $4.8 \%$, respectively. Other reported chronic diseases included pulmonary problems (3.0\%), liver problems (4.0\%), renal problems (2.7\%), infectious problems (4.5\%), cancer (1.5\%), and stroke (1.0\%).

\begin{tabular}{|c|c|}
\hline Characteristics & Results \\
\hline \multicolumn{2}{|l|}{ Sex } \\
\hline Men & $370(93.4)$ \\
\hline Women & $26(6.6)$ \\
\hline \multicolumn{2}{|l|}{ Ethnicity } \\
\hline Minority Chinese & $9(2.2)$ \\
\hline Han Chinese & $387(97.8)$ \\
\hline \multicolumn{2}{|l|}{ Marital status } \\
\hline Married (divorced and widowed included) & $315(79.5)$ \\
\hline Unmarried & $81(20.5)$ \\
\hline \multicolumn{2}{|l|}{ Age group, y } \\
\hline $20-30$ & $69(17.4)$ \\
\hline $30-40$ & $161(40.6)$ \\
\hline $40-50$ & $117(29.5)$ \\
\hline $50-60$ & $49(12.5)$ \\
\hline \multicolumn{2}{|l|}{ Education } \\
\hline Elementary school & $59(14.8)$ \\
\hline Junior high school & $136(34.3)$ \\
\hline Senior high school & $188(47.4)$ \\
\hline College or above & $13(3.2)$ \\
\hline \multicolumn{2}{|l|}{ Years of employment as a taxi driver } \\
\hline $1-5$ & $52(13.1)$ \\
\hline $5-10$ & $203(51.2)$ \\
\hline$\geq 10$ & $141(35.7)$ \\
\hline
\end{tabular}

\begin{tabular}{|c|c|}
\hline Characteristics & Results \\
\hline \multicolumn{2}{|l|}{ Currently smoking } \\
\hline Yes & $297(76.5)$ \\
\hline No & $99(23.5)$ \\
\hline $\begin{array}{l}\text { Drinking alcohol frequently ( } \geq 3 \text { times per } \\
\text { week) }\end{array}$ & $41(10.3)$ \\
\hline Irregular diet & $265(66.9)$ \\
\hline Working time, $h$ & $10.5 \pm 1.2$ \\
\hline Sleeping time, $h$ & $6.9 \pm 1.0$ \\
\hline \multicolumn{2}{|l|}{$\begin{array}{l}\text { Regular exercise in the last } 6 \text { months ( } \geq 3 \text { times } \\
\text { per week) }\end{array}$} \\
\hline Yes & $59(14.8)$ \\
\hline No & $337(85.2)$ \\
\hline
\end{tabular}

\begin{tabular}{lc}
\hline \multicolumn{2}{l}{ Table 3. Self-reported General Health Status } \\
\hline Characteristics & $\begin{array}{c}\text { Number of People } \\
(\%),(95 \% \text { CI })\end{array}$ \\
\hline Physical and emotional wellbeing & $17(4.3),(2.3-6.3)$ \\
\hline Excellent & $123(31),(26.4-35.6)$ \\
\hline Good & $166(41.9),(37-46.8)$ \\
\hline Fair & $83(20.9),(16.9-24.9)$ \\
\hline Poor & $7(1.7),(0.4-3)$ \\
\hline Very poor & \\
\hline Morbidity & $217(54.8),(49.9-59.7)$ \\
\hline Discomfort within 2 weeks & $189(47.7),(42.8-52.6)$ \\
\hline Diagnosed with chronic disease during \\
the past 12 months \\
Infectious and parasitic disease & $18(4.5),(2.5-6.5)$ \\
\hline Cancer & $6(1.5),(0.3-2.7)$ \\
\hline Stroke & $4(1.0),(0.02-2)$ \\
\hline Diabetes & $35(8.8),(6-11.6)$ \\
\hline Heart disease & $19(4.8),(2.7-6.9)$ \\
\hline Chronic pulmonary disease & $12(3.0),(1.3-4.7)$ \\
\hline Hypertension & $72(18.2),(14.4-22)$ \\
\hline Gastroenteritis & $103(26.0),(21.7-30.3)$ \\
\hline Chronic liver disease & $16(4.0),(2.1-5.9)$ \\
\hline Chronic renal disease & $11(2.7),(1.1-4.3)$ \\
\hline Arthritis & $73(18.4),(14.6-22.2)$ \\
\hline
\end{tabular}


Yang Yet al.

Table 4. Self-reported Symptoms

\begin{tabular}{lc}
\hline Characteristics & $\begin{array}{c}\text { Number of People } \\
(\%),(95 \% \text { CI })\end{array}$ \\
\hline Nervous system symptoms & $197(49.7),(44.8-54.6)$ \\
\hline Fatigue & $93(23.5),(19.3-27.7)$ \\
\hline Headache & $75(18.9),(15-22.8)$ \\
\hline Particular irritability & $62(15.6),(12-19.2)$ \\
\hline Insomnia & $45(11.3),(8.2-14.4)$ \\
\hline Dizziness & $57(14.3),(10.9-17.7)$ \\
\hline Anxiety & $61(15.4),(11.8-19)$ \\
\hline Dreaminess & $72(18.1),(14.3-21.9)$ \\
\hline Hypomnesis & \\
\hline Digestive system symptoms & $93(23.5),(19.3-27.7)$ \\
\hline Anorexia & $43(10.8),(7.7-13.9)$ \\
\hline Nausea and vomiting & $103(26.0),(21.7-30.3)$ \\
\hline Dyspepsia & $32(8.1),(5.4-10.8)$ \\
\hline Constipation & $21(5.3),(3.1-7.5)$ \\
\hline Diarrhea & \\
\hline Renal system symptoms & $87(21.9),(17.8-26)$ \\
\hline Frequent micturition & \\
\hline Respiratory system symptoms & $104(26.2),(21.9-30.5)$ \\
\hline Cough & $27(6.8),(4.3-9.3)$ \\
\hline Expectoration & $107(27),(22.6-31.4)$ \\
\hline Sore throat & $39(9.8),(6.9-12.7)$ \\
\hline Asthma & $93(23.5),(19.3-27.7)$ \\
\hline Chest congestion & $11(2.7),(1.1-4.3)$ \\
\hline Dry throat & \\
\hline Cardiovascular system symptoms & \\
\hline Weart palpitation & \\
\hline Scapulohumeral periarthritis & \\
\hline
\end{tabular}

Table 5. Intention to Seek Health Examination and Participation in Health Education

\begin{tabular}{lc}
\hline Characteristics & $\begin{array}{c}\text { Number of People } \\
(\%),(95 \% \text { CI })\end{array}$ \\
\hline Health examination needs & $357(90.1),(87.1-93)$ \\
\hline $\begin{array}{l}\text { Necessary } \\
\text { Unnecessary }\end{array}$ & $39(9.9),(7-12.8)$ \\
$\begin{array}{l}\text { Received message about health educa- } \\
\text { tion before }\end{array}$ & $71(17.9),(14.1-21.7)$ \\
$\begin{array}{l}\text { Message was helpful } \\
\text { Way of receiving health education } \\
\text { message }\end{array}$ & $62(87.3),(84-90.6)$ \\
\hline $\begin{array}{l}\text { Radio TV Internet Book } \\
\text { Lecture in the community }\end{array}$ & $37(52.1),(47.2-57)$ \\
\hline Doctor & $31(43.6),(38.7-48.5)$ \\
\hline Other & $23(32.4),(27.8-37)$ \\
\hline
\end{tabular}

\subsection{Self-reported Symptoms}

The significant self-reported symptoms included fatigue, waist and back pain, headache, dyspepsia, and dry throat that affected $49.7 \%, 26.2 \%, 23.5 \%, 26 \%$, and $27 \%$ of respondents, respectively.

\subsection{Intention to Seek Health Examination and Par- ticipation in Health Education}

Regarding education, as shown in Table 5, 90.1\% of subjects thought that it was necessary to receive regular health examinations. Seventy-one (17.9\%) subjects indicated that they had been given information about health education, and significantly, more than $87 \%$ subjects who had been given information about health education reported that the information had been helpful. In total, $43.6 \%$ of subjects indicated that lecture in the community was an important way to receive a health education message.

\section{Discussion}

Self-rated health (SRH) is based on a simple questionnaire on which people are asked to rate their own overall health. SRH is also termed "general health" because the phrase refers to an individual's perception of his or her own health (6). Although SRH is a subjective consciousness about personal health rather than an objective measure of health, this factor has been reported to be a predictor of morbidity and mortality, even after controlling for other related factors (7). This study highlighted taxi drivers' health status as follows. Most subjects rated their health positively and $35.3 \%$ rated their health as very good or good whereas $22.6 \%$ of subjects reported bad or very bad health. The study presents two main findings. First, the prevalence rate of hypertension (18.2\%), lumbar muscle strain-related arthritis (18.4\%), gastroenteritis (26\%), and diabetes mellitus (8.8\%) was high. Second, a significant number of subjects had symptoms such as headache, fatigue, anorexia, dyspepsia, dry throat, chest congestion, and waist and back pain.

Hypertension is one of the most important risk factors for stroke, coronary heart disease, and renal disease ( 8 , 9 ). It has been hypothesized that by $2025,29.2 \%$ of the world's adult population would suffer from hypertension and most affected individuals would be found in developing countries (10). Our study indicates that the prevalence rate of hypertension among taxi drivers was $18.2 \%$ whereas the overall prevalence rate of hypertension in Chinese adults was $18.1 \%$ in 2004 (11). Taxi drivers experience decreased physical activity, hard work, job stress, and a disruption in normal sleep and waking patterns, which might explain the higher prevalence of hypertension among taxi drivers.

Gastritis is a serious medical problem for many people worldwide and untreated gastritis can cause a peptic ulcer or gastric cancer (12). Stress, an irregular lifestyle, 
certain eating habits, and sedentary work are associated with a higher prevalence of gastritis among taxi drivers.

Taxi drivers are constrained to a very limited space behind the wheel, and they have to assume driving postures without too much backward inclination to provide more room for passengers. Due to the long driving time (on average, 10 hours per day for 26 days per month), taxi drivers have to continuously work in stationary postures for a long period. Prolonged sitting behind the wheel can cause significant postural strains on the back muscles and the lumbar spine $(13,14)$. Taxi drivers are exposed to whole-body vibration on a daily basis, which results in joint pain, swelling, muscle stiffness, and back pain (15, 16). Our studies also confirmed these results. Furthermore, taxi drivers are exposed to off-gas air pollution and a hazardous work environment, which can cause respiratory system problems. Similar results were found in other studies (17).

It is well known that exercise and a healthy diet are determinants of better SRH (18). Numerous factors including stress, depression, bad habits (such as alcohol abuse, excessive smoking, staying up late, and a lack of exercise), and air pollution are correlated with the development and progression of many diseases especially cardiopathy, diabetes mellitus, and tumors (19). Promoting healthy lifestyles through health education is recognized as effective by many researchers (20-22). However, in our study, approximately $76.5 \%$ of the respondents were current smokers, $10.3 \%$ drank alcohol frequently, 66.9\% had irregular diets, and 85\% reported no regular exercise. Thus, using health education interventions to improve knowledge and change behavior seems necessary. Regarding health education needs, taxi drivers expressed a significant need as only $17.9 \%$ of our study participants had received a health education message, which indicated the need for a greater effort in this area.

A strength of the study is its representativeness for one nation, but several limitations to this study are worth noting. First, the study was a population-based cross-sectional survey, and the cross-sectional design hampered causality inference. Second, the measurements were selfreports and thus, were subjected to information and recall bias. Third, although quality of life is an important parameter in population health status, quality of life was not examined throughly in our study. While the study was conducted on a limited number of subjects, interestingly, the outcome revealed several facts about the health status of taxi drivers that would help in the promotion of their socioeconomic conditions. Based on the findings, effective programs are needed to improve the health of this special occupational group.

\section{Acknowledgements}

We heartily acknowledge the cooperation and support of the taxi drivers who participated in our study.

\section{Authors' Contribution}

All authors contributed equally in writing and editing the manuscript.

\section{Financial Disclosure}

The authors declared that they had no conflict of interests.

\section{Funding/Support}

There was no funding or supports.

\section{References}

1. World Health Organization.. Health interview surveys: Towards international harmonization of methods and instruments.Copenhagen: WHO Office for Europe; 1996

2. Waters HR, Anderson GF, Mays J. Measuring financial protection in health in the United States. Health Policy. 2004;69(3):339-49.

3. Cheung K, Oemar M, Oppe M, Rabin R. EQ-5D user guide: basic information on how to use EQ-5D.Rotterdam:EuroQol Group; 2009.

4. Forero CG, Vilagut G, Adroher ND, Alonso J, E. SEMeD/MHEDEA Investigators. Multidimensional item response theory models yielded good fit and reliable scores for the Short Form-12 questionnaire. JClin Epidemiol. 2013;66(7):790-801.

5. Vilagut G, Forero CG, Pinto-Meza A, Haro JM, de Graaf R, Bruffaerts $\mathrm{R}$, et al. The mental component of the short-form 12 health survey (SF-12) as a measure of depressive disorders in the general population: results with three alternative scoring methods. Value Health. 2013;16(4):564-73.

6. Eriksson I, Unden AL, Elofsson S. Self-rated health. Comparisons between three different measures. Results from a population study. Int J Epidemiol. 2001;30(2):326-33.

7. Benyamini Y, Leventhal H, Leventhal EA. Self-rated oral health as an independent predictor of self-rated general health, self-esteem and life satisfaction. Soc Sci Med. 2004;59(5):1109-16.

8. Whitworth JA, World Health Organization ISOHWG. 2003 World Health Organization (WHO)/International Society of Hypertension (ISH) statement on management of hypertension. J Hypertens. 2003;21(11):1983-92.

9. Prospective Studies C, Lewington S, Whitlock G, Clarke R, Sherliker P, Emberson J, et al. Blood cholesterol and vascular mortality by age, sex, and blood pressure: a meta-analysis of individual data from 61 prospective studies with 55,000 vascular deaths. Lancet. 2007;370(9602):1829-39.

10. Kearney PM, Whelton M, Reynolds K, Muntner P, Whelton PK, He J. Global burden of hypertension: analysis of worldwide data. Lancet. 2005;365(9455):217-23.

11. Wu Y, Huxley R, Li L, Anna V, Xie G, Yao C, et al. Prevalence, awareness, treatment, and control of hypertension in China: data from the China National Nutrition and Health Survey 2002. Circulation. 2008;118(25):2679-86.

12. Di Mario F, Franzè A, Cavallaro LG. Non-invasive approach to diagnosis of upper gastrointestinal diseases. AREA QUALITà Srl. 2008;1:5-64.

13. Gallais L. Low back pain and risk factors for low back pain in car drivers.Southampton: University of Southampton; 2008.

14. Chen JC, Chan WP, Katz JN, Chang WP, Christiani DC. Occupational and personal factors associated with acquired lumbar spondylolisthesis of urban taxi drivers. Occup Environ Med. 2004;61(12):992-8.

15. Chen JC, Chang WR, Chang W, Christiani D. Occupational factors associated with low back pain in urban taxi drivers. Occup Med (Lond). 2005;55(7):535-40

16. Alperovitch-Najenson D, Santo Y, Masharawi Y, Katz-Leurer M, Ushvaev D, Kalichman L. Low back pain among professional bus drivers: ergonomic and occupational-psychosocial risk factors. Isr Med Assoc J. 2010;12(1):26-31. 
17. Miller-Schulze JP, Paulsen M, Toriba A, Tang N, Hayakawa K, Tamura $\mathrm{K}$, et al. Exposures to particulate air pollution and nitro-polycyclic aromatic hydrocarbons among taxi drivers in Shenyang, China. Environ Sci Technol.2010;44(1):216-21.

18. Sodergren M, Sundquist J, Johansson SE, Sundquist K. Physical activity, exercise and self-rated health: a population-based study from Sweden. BMC Public Health. 2008;8:352.

19. Liu BY, Ren N, Yang H. Research of the relationship between occupational stress and multiple cardiovascular diseases. J Hyg Res. 2006;35:12-5.

20. Wong WP, Yeung M, Loh S, Lee M, Ghazali F, Chan CJ, et al. Stroke- related knowledge, lifestyle behaviours and health beliefs in Singaporean Chinese: Implications for health education. Health Educ J. 2013;72(4):386-97.

21. Harris J. Physical education teacher education students' knowledge, perceptions and experiences of promoting healthy, active lifestyles in secondary schools. Physic Educ Sport Pedag. 2013(aheadof-print):1-15.

22. Saffari M, Amini N, Eftekhar Ardebili H, Sanaeinasab H, Mahmoudi M, Piper CN. Educational intervention on health related lifestyle changes among Iranian adolescents. Iran J Public Health. 2013;42(2):172-81. 